\title{
The effects of long-term thermal load on the stability of the lining of a deep underground waste repository
}

\author{
J. Pacovský \& R. Vašíček \\ Centre of Experimental Geotechnics, Faculty of Civil Engineering, \\ Czech Technical University in Prague, Czech Republic
}

\begin{abstract}
The long-term stability of the lining of disposal tunnels is a precondition for the safe removal and reprocessing of spent nuclear waste from deep underground repositories in the near or more distant future. The reason for removing containers with radioactive waste from such repositories lies in the potential discovery of presently unavailable "perfect" technology for its reprocessing. The stability problems of tunnel linings exposed to the long-term thermal load generated by the waste in the disposal container is the subject of the European TIMODAZ project. Research is being carried out by means of physical modelling. This paper describes the design, construction and currently available results of a laboratory model which has been built at the Centre of Experimental Geotechnics and an "in-situ" model which has been built at the Josef Underground Educational Facility.
\end{abstract}

Keywords: radioactive waste, reprocessing, thermal load, long-term stability, physical model.

\section{Introduction}

TIMODAZ (Thermal Impact on the Damaged Zone around a Radioactive Waste Disposal in Clay Host Rocks) is a pan-European project and forms part of the 6th EURATOM Framework Programme. The project involves the close participation of 14 European universities and research institutes from a total of 8 European countries (BE, FR, CH, DE, NL, ES, CZ, UK). 
This extensive European project is aimed at researching the impact of longterm thermal effects on a multi-barrier system; in particular on a natural barrier composed of clay rocks (soils) e.g. boom clay, opalinus clay and CallovoOxfordian argillite. The study of the various problems involved is based on the thermal loading of a multi-barrier system (i.e. engineered, technological and natural barriers) up to $90^{\circ} \mathrm{C}$ for a time period of 20 to 50 years following the disposal of the container.

As far as the Czech Republic is concerned, it is presumed that the natural barrier will be composed of a granitic rock continuum (granite) rather than a clay rock continuum. The difference between the Czech concept for the selection of a natural barrier i.e. granite-based, unlike that envisaged by the majority of the other partners in the project (clay-based), resulted, after extensive discussion, in the creation of a separate project entitled Lining Stability under Thermal Load the objective of which is the physical modelling of the limit load acting upon the lining.

\section{Research objective}

The objective of the research is to verify whether long-term thermal loading may induce such deformations that could cause a loss in the shape stability of the disposal tunnel lining or such a load (stress) within the concrete lining of the disposal tunnel that the strength characteristics of the concrete are exhausted thus negatively affecting its stability.

Physical modelling is the only experimental tool which is capable of fully addressing all the issues involved. Two physical models have been assembled; one is situated in the underground silo of the laboratory of the Centre of Experimental Geotechnics (CEG) in Prague [1] - the laboratory physical model; the other in the underground laboratory of the Josef UEF near Dobřiš [2] - the "in situ" physical model. Each of the physical models investigates a different extreme case in terms of tunnel lining loading.

The model situated in the underground silo of the CEG laboratory (Fig. 1) has been designed to study the effect of thermal loading on the disposal tunnel lining and has been constructed so as to allow lining deformation in the direction towards the surrounding environment (compacted sand). Heat effects and volume changes could result either in the insertion of segments of the lining or indeed the whole of the lining structure into the surrounding environment or deformation in the direction towards the inside tunnel profile. The research hopes to answer the question as to whether lining deformation caused by thermal load might attain such values that it induces a reduction in the shape stability of the lining. In this case, since the lining is allowed to deform, it does not suffer from such a high level of stress resulting from thermal load. Therefore, the principal monitored parameters consist of temperature and deformation.

The "In situ" physical model conversely is aimed at the study of limit loading. The model is assembled in a rock continuum (hard tuffitic rocks). The space between the circular lining and the rock is backfilled with concrete (Fig. 2). This method of construction minimises the occurrence of lining deformation but 


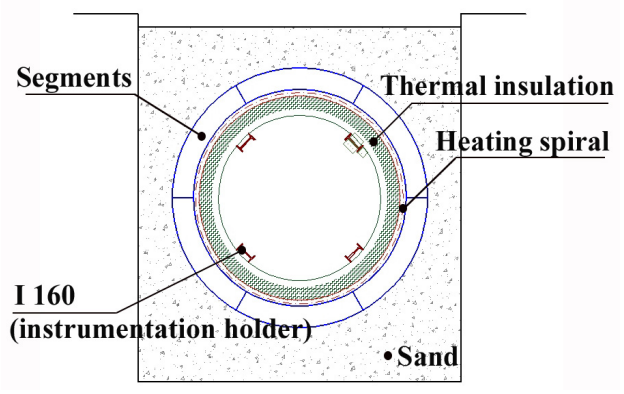

Figure 1: $\quad$ Laboratory model - cross-section.

Compacted concrete

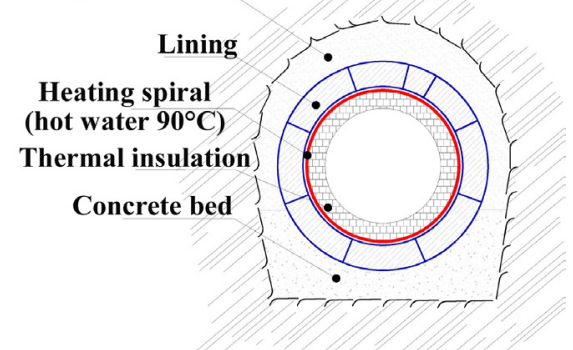

Figure 2: In situ model - cross-section.

maximises the magnitude of the various stresses arising within the lining and its vicinity due to thermal loading. The principal monitored parameters in this case consist of temperature and stress.

\section{Construction of the laboratory physical model at the Centre of Experimental Geotechnics}

The assembly of the laboratory model, which took from April to October 2007, preceded that of the "in situ" model. The experiment was launched on $20^{\text {th }}$ November 2007.

\subsection{Model design}

The laboratory model was built using a prefabricated lining produced in Slovakia. There were several reasons why the original Belgian lining designed for the disposal tunnel was not employed. The intention of building the physical model was, primarily, to obtain construction-related experience, to test the instrumentation of the model using meters as well as to test the functionality of the specially-designed heating system. This, subsequently, produced considerable financial savings. On the other hand, it is evident that the model serves solely for the study of processes that are currently underway, and that the 
measured values of the various monitored parameters cannot be applied for the dimensioning of the actual lining of disposal tunnels. The model was built of 3 rings each consisting of 6 segments. The outside diameter of the rings measures $1980 \mathrm{~mm}$, the inside diameter $1660 \mathrm{~mm}$, the segment width $500 \mathrm{~mm}$ and the segment thickness $160 \mathrm{~mm}$. The material used was common reinforced concrete. Each segment weighs $195 \mathrm{~kg}$.

\subsection{Model construction}

The model was assembled in the CEG laboratory's experimental underground silo which measures $2500 \times 2500 \times 2800 \mathrm{~mm}$ (where $2800 \mathrm{~mm}$ is the depth of the silo).

The concrete walls of the silo were insulated using polystyrene boards and a retention wall made up of Ytong-type blocks. This arrangement was applied to minimise heat escape from the silo.

To allow for the installation of displacement meters (for deformation measurement) the silo walls were fitted with beams mounted independently of the model. It was assumed that the longitudinal deformation of the model would be minimised by the front steel frame.

The model was assembled stage by stage accompanied by the gradual backfilling of the side sections with sand. The individual layers of sand were compacted manually, Fig. 3.

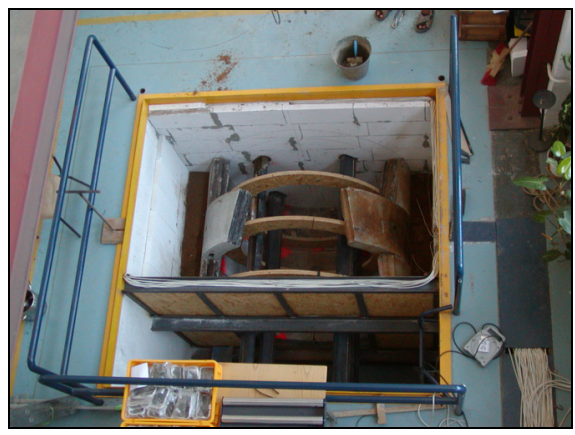

Figure 3: Gradual construction of the lining.

\subsection{Heating system}

The inside surface of the lining served for the installation of a heating system manufactured by Revel Ltd, incorporating a plastic tube heating spiral with water as the circulating heating medium (Fig. 4). This system allows the heating of the inside concrete lining surface to a final temperature of $90^{\circ} \mathrm{C}$. The water is heated by two electric boilers controlled by an automated control unit. The heating spiral inside the model, as well as the model face, is protected by means of thermal insulation to minimise thermal loss (Fig. 5). 


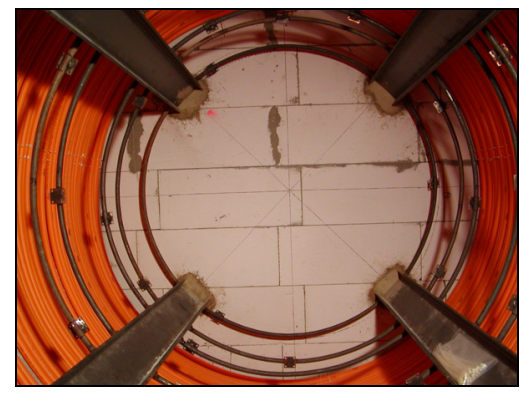

Figure 4: Heating spirals.

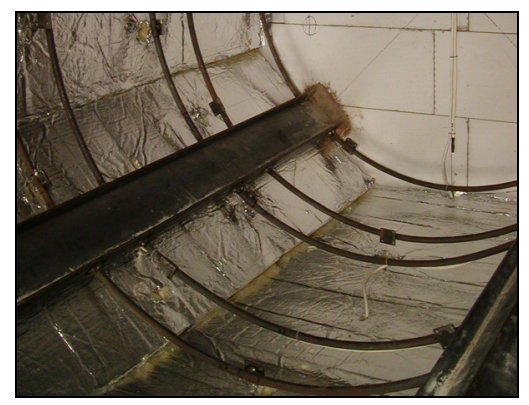

Figure 5: Insulation of the heating system.

\subsection{Instrumentation}

The model is instrumented by means of a total of 97 thermometers and 30 deformation (displacement) meters.

Measurement is automated; data is recorded once every 10 minutes. The experiment is connected to the Internet so that the measurement results are readily available not only to the various partners involved, but also to the general public (http://ceg.fsv.cvut.cz, www.uef-josef.eu).

A spatial diagram of the layout of the instrumentation of the TIMODAZ experiment is available via the website.

\section{Construction of the "in situ" physical model at the Underground Educational Facility Josef}

The construction of the "in situ" model commenced in February 2008 and was completed in October 2008.

\subsection{Model design}

The model is made up of four rings each consisting of 8 segments and each of which in turn is fitted with a key segment at its crown. Based on the requirements set by the project coordinator, SCK-CEN Belgium, two types of 
rings, differing in terms of structure, were used in the construction of the model. The first type of ring (type "A") was made of high-strength reinforced-concrete with a uni-axial compressive strength of 120MPa. Type "B" was made of concrete with a uni-axial compressive strength of 95MPa and fitted with two compressible structural inserts (INOX foam panels) with a compressive strength of $40 \mathrm{MPa}$ and a thickness of $50 \mathrm{~mm}$ which allows compression of up to $3 \mathrm{~mm}$. This modification allows the use of lower quality concrete.

The model was constructed using 2 rings of type " $A$ " and 2 of type "B". The width of individual segments is $500 \mathrm{~mm}$, which makes the total length of the model $2000 \mathrm{~mm}$. The thickness of the segments is $300 \mathrm{~mm}$, the inside diameter of the rings $1900 \mathrm{~mm}$ and the outside diameter $2500 \mathrm{~mm}$. The total weight of the ring amounts to $2540 \mathrm{~kg}$ with a segment weight of $250-320 \mathrm{~kg}$.

\subsection{Model construction}

The site selected for the model was a short niche whose profile was sufficient for the construction of a model with an outside diameter of $2500 \mathrm{~mm}$. This niche was driven into very hard tuffitic rocks with a uni-axial compressive strength of 220 $-240 \mathrm{MPa}$.

Prior to the commencement of construction, a network of boreholes was drilled into the surrounding rock to house thermometers.

After the installation of thermometers in the lower part of the model, the floor was concreted and formwork for the concreting of the lower disposal trough was erected upon it (Fig. 6). The next step was the installation of contact stress meters - hydraulic pressure cells. The disposal trough was subsequently concreted. All the various meters were connected to data loggers immediately after installation. The lower part of the model was then positioned upon the disposal trough (Fig. 7).

Assembly proceeded in the direction away from the face of the niche. The space between the face and the first ring, as well as the lateral space between the rings and the rock, was backfilled with concrete. At the same time, additional meters were installed in boreholes within the rock at points where the rock

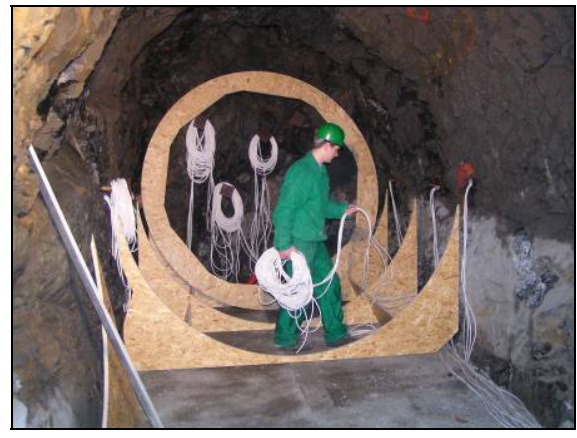

Figure 6: Disposal trough formwork. 
makes contact with the concrete filler and within the infill concrete; the meters were then connected to data loggers. The vault was assembled on a mobile formwork; all the empty spaces between the rock and the lining were backfilled with concrete and natural vault activation occurred following the removal of the formwork (Fig. 8).

The outside face of the physical model was secured against deformation in the longitudinal direction by a steel frame. The front face of the model is glazed and features a potential entry point to the internal chamber.

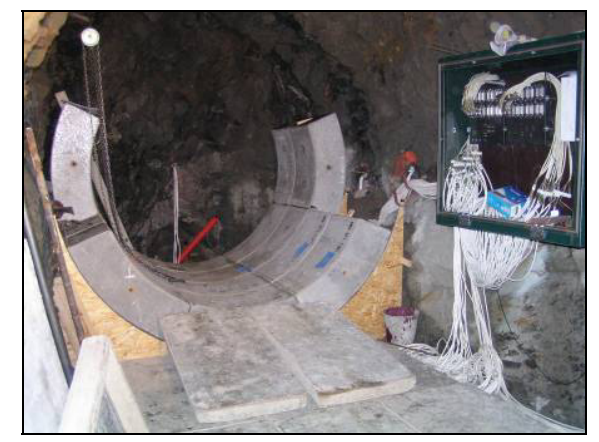

Figure 7: Assembly of the lower part of the model.

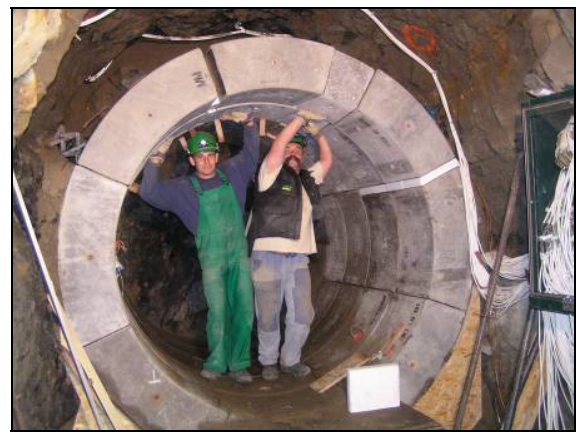

Figure 8: Naturally activated lining vault.

\subsection{Heating system}

The heating system is identical to that used in the laboratory physical model Fig. 9 (see par. 3.3).

\subsection{Instrumentation}

The whole of the experiment is fully instrumented. Over 250 sensors measure the most significant parameters: temperature, stress (load) and deformation (displacement). Moreover, the power consumption of the heating system is also measured. 


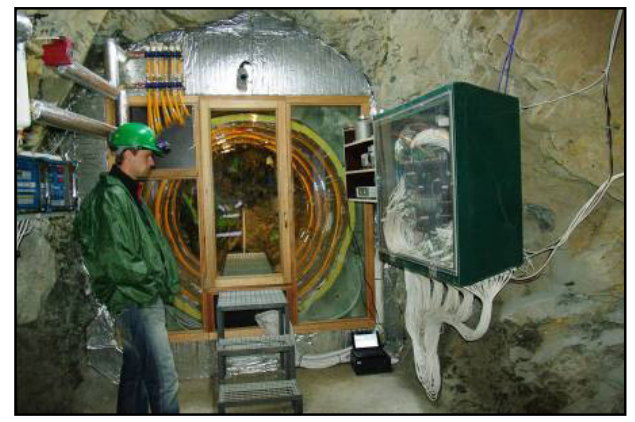

Figure 9: Thermal insulation inside and outside the model.

Measurement is automated, the data being recorded once every 10 minutes. The experiment is connected to the Internet so that measurement results are readily available not only to various partners involved, but also to the general public.

A spatial diagram of the layout of the instrumentation of the TIMODAZ experiment is available via the website.

\section{Measurement procedures}

Research into the problems of radioactive waste disposal is unique due to the requirement for the long-term validity of the results obtained. In ordinary engineered structures, the required service life ranges in the order of dozens or, at most, hundreds of years; for deep underground repositories, which are also engineered structures, even though of a highly special nature, the required service/safe functioning life ranges in the order of hundreds of thousands of years.

Consequently, such research must apply all the experimental tools available among which physical modelling ranks as one of the most effective.

Clearly, experimental research using physical models cannot be performed in real time i.e. for hundreds of thousands of years, where the design of multibarrier systems and deep underground repositories would be finalised only after such time has elapsed. Such research, however, must be, at least, performed, if possible, in a real environment, with real materials and at a scale of 1:1 (socalled physical models of the "first type"). In order to approximate the time frame, the procedures should apply extreme and cyclical loading, cumulated effects and so on.

The loading procedures applied with regard to the two physical models differed.

In the laboratory model, the lining was heated to a temperature of $90^{\circ} \mathrm{C}$ immediately without any intermediate steps being applied.

As for the "in situ" experiment, the demand (set by SCK-CEN Belgium) that the temperature difference between the inside and outside of the lining could not exceed $30^{\circ} \mathrm{C}$ had to be met. Therefore, the "in situ" model had to be thermally 
loaded on a step-by-step basis, in successive phases: $40^{\circ} \mathrm{C}$ (phase 1 ), $60^{\circ} \mathrm{C}$ (phase 2), $70^{\circ} \mathrm{C}$ (phase 3 ), $80^{\circ} \mathrm{C}$ (phase 4 ), $90^{\circ} \mathrm{C}$ (phase 5). At the time of writing preparations were being made for the implementation of the final loading step $\left(90^{\circ} \mathrm{C}\right)$.

In the future, following an evaluation of the data obtained from the loading procedures applied to-date, shock cyclic loading is planned for both experiments to ensure that the extreme loading conditions will be even more intensive.

\section{Certain results to date}

The two experiments have already provided over 20 million measured pieces of data. The data is subjected to continuous evaluation and is being used for the mathematical modelling of the various issues under investigation.

\subsection{Laboratory physical model}

The laboratory model provides two principal outputs - the development of both temperature and deformation.

Figure 10 illustrates temperature development in one of the measured profiles. The time pattern shows that during the whole period of thermal loading there were three failures caused by power cuts at CEG or by the switching off of the experiment to allow the replacement of the heating system pumps.
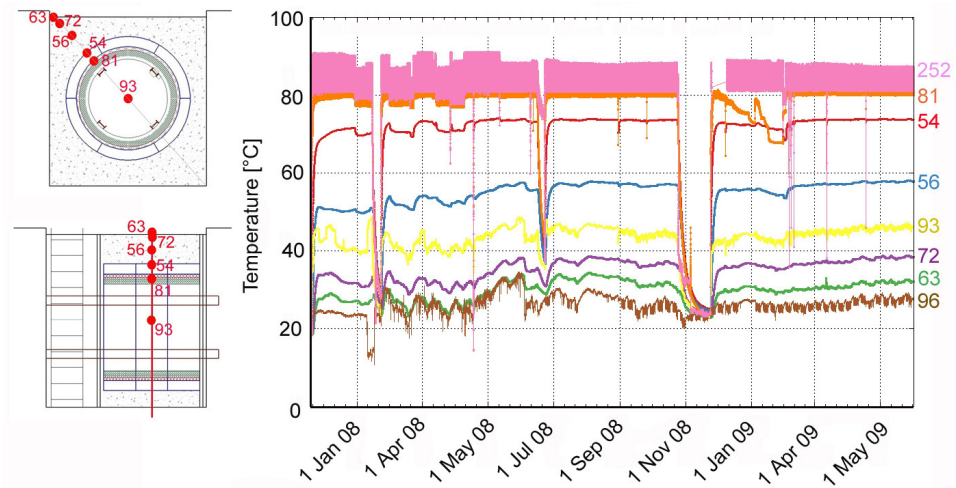

Figure 10: Temperature development in the middle of the experiment since its launch.

The graph shows that the development of the measured values was affected not only by shutdowns in the operation of the experiment, but also by temperature changes in the laboratory (day/night, seasonal differences).

Figure 11 records deformation development in one of the longitudinal sections. The results show that it took one year for lining deformation to cease. A further fact worthy of note is that cooling during thermal loading interruption caused rapid deformation increase; after the experiment was switched on again the deformation values returned to their original values equally rapidly. 

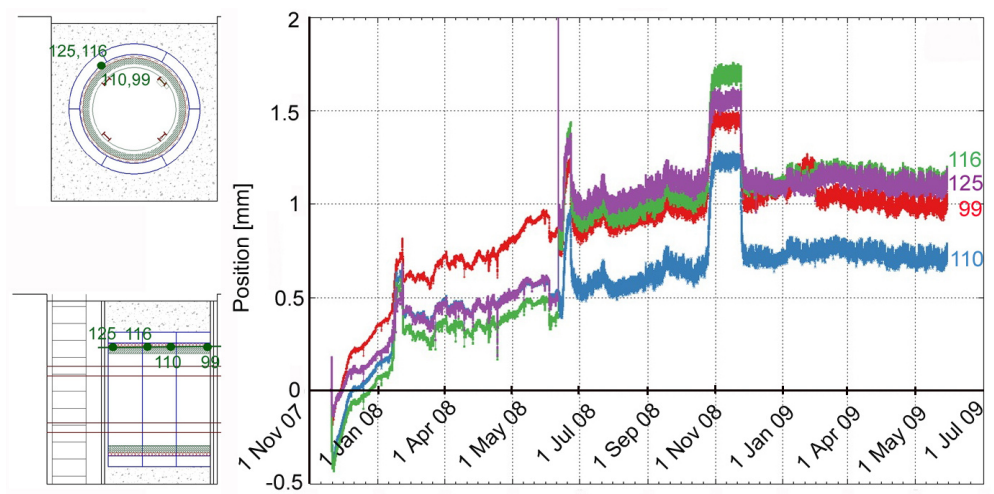

Figure 11: Development of deformation changes in the longitudinal direction.

\section{2 "In situ" physical model}

As for the "in situ" experiment, measurement commenced immediately after the installation of individual meters. A number of interesting results were obtained as early as during the hydration of the concrete filling the space between the rock and the lining, i.e. prior to the launch of thermal loading. Thermal loading was applied by means of individual loading stages, Fig. 12 .

An example of temperature increase in the rock mass during phase 1 is presented in Fig. 13.

An example of an increase in stress inside the lining segments during phase 2 is displayed in Fig. 14.
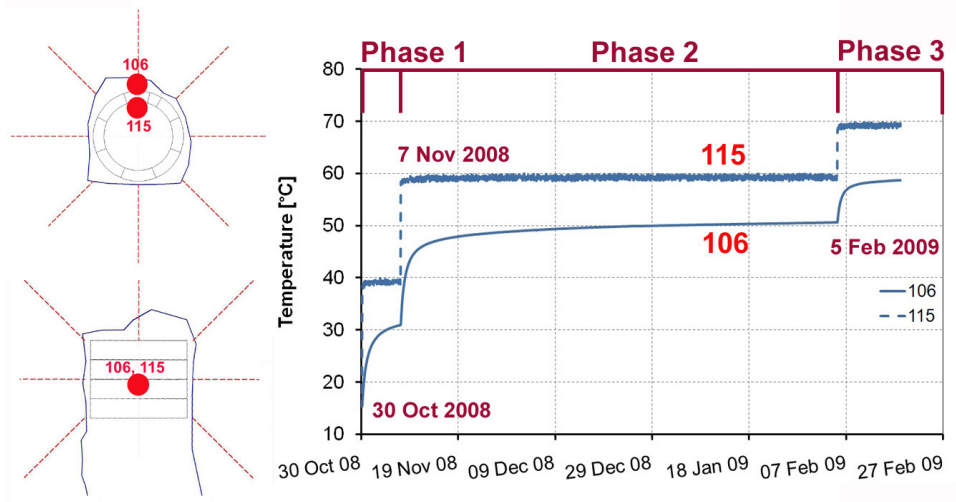

Figure 12: Temperature gradient following step-by-step loading. 

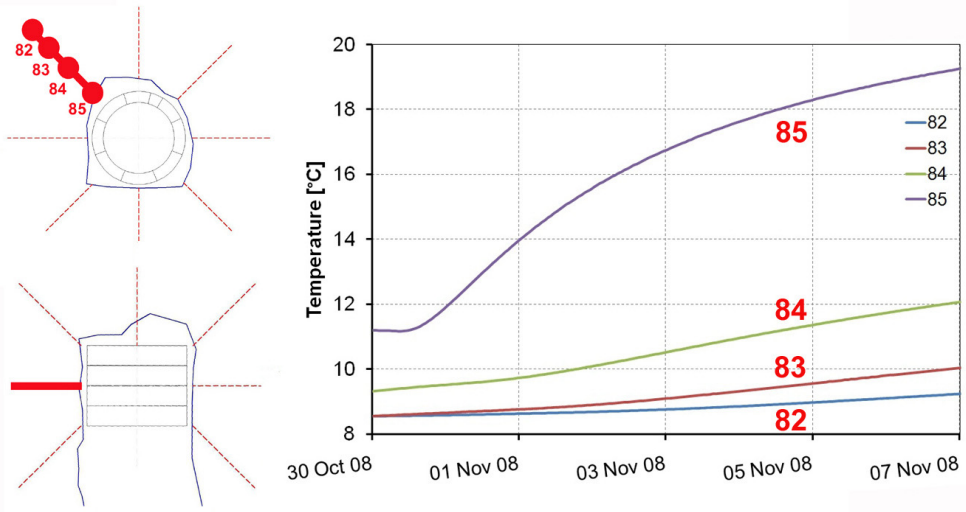

Figure 13: Temperature increase within the rock mass - phase 1.

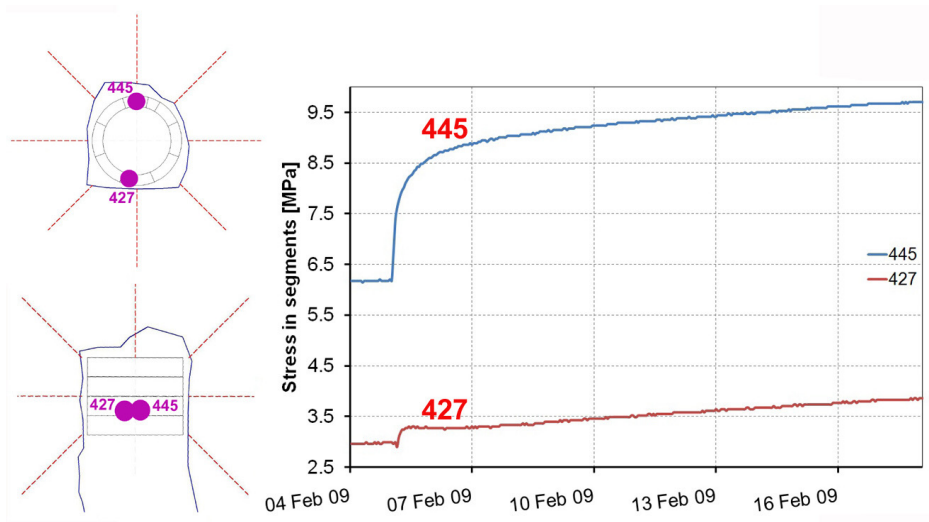

Figure 14: Stress increase within concrete segments - phase 2.

\section{Conclusion}

Research into the stability of the lining of disposal tunnels for high-level radioactive waste containers has not yet been fully subjected to experimental verification. In the field of classic underground structures, no adequate level of interest has been shown in the effects of temperature changes on the redistribution of the various loads within the rock mass (i.e. within the natural barrier) and the resulting induced load changes affecting the underground structure. Certain works [3] claim that even a small change in temperature causes non-negligible changes in the loading of an underground structure.

It is hoped that physical modelling at a scale of 1:1 will make a significant contribution towards the study of such issues. The results obtained from the physical model experiment constructed at the Josef Underground Educational Facility to-date, prior to reaching the planned maximum thermal load, are 
relatively surprising. Should the resulting stress approach the strength characteristics of the concrete lining (for both types of lining used), the whole lining construction concept would have to be reconsidered.

\section{Acknowledgements}

The author would like to thank the European TIMODAZ project for financial support. TIMODAZ is co-funded by the European Commission (EC) as part of the sixth EURATOM research and training Framework Programme (FP6) on nuclear energy.

In addition, this extensive research project could not have taken place without support from the "Institutional research plan MSM6840770031 - Complex System of Methods for Directed Design and Assessment of Functional Properties of Building Materials"

\section{References}

[1] Centre of Experimental Geotechnics, http://ceg.fsv.cvut.cz

[2] Underground Educational Facility Josef, http://www.uef-josef.eu

[3] The PRACLAY Project, Demonstration Test on the Belgian Disposal Facility Concept for High Activity Vitrified Waste. In: Nuclear Science and Technology, EUR 18047 EN, 1998, Brussels, Belgium. 